\title{
An assessment of the government of India's initiative on contraceptives at the doorstep by Accredited Social Health Activists (ASHAs): Recommendations for national scale-up
}

\author{
Sharmistha Basu ${ }^{*}$, Mackenzie Green ${ }^{2}$ and Bitra George ${ }^{3}$ \\ ${ }^{1}$ FHI 360, New Delhi, India, now with Population Council, New Delhi, India \\ ${ }^{2}$ FHI360, Durham, North Carolina, now with ARCH at Helen Keller International, Cambodia \\ ${ }^{3}$ FHI 360, New Delhi, India
}

\begin{abstract}
Objective: The Government of India (GOI) piloted a new initiative in 17 states where Accredited Social Health Activists (ASHAs) delivered contraceptives directly to households for a small fee. This paper details an assessment of the pilot with the aim of informing the GOI's national scale-up of the initiative.

Methods: A mixed-method approach was used in May 2012 to assess operational issues, barriers and facilitators of implementation, and initiative experiences in 6 states. Participants included ASHAs, community women, and managers and other key implementers.

Results: Community women and ASHAs found the initiative favorable and managers were positive about long term success. The assessment uncovered challenges in the supply chain, the packaging of the initiative's contraceptives, communication efforts, and orientation and reporting.

Conclusion: The initiative is a promising strategy to address unmet need and to increase the uptake of birth-spacing methods. Assessment recommendations can inform and strengthen other community-based family planning programs.
\end{abstract}

\section{Introduction}

Many programs are exploring alternative ways to deliver family planning services, such as offering them in the community as well as clinic-based settings. Studies from India, Bangladesh, and several African countries show that community health workers (CHWs) can safely and effectively provide a range of contraceptive methods, even when CHWs have low or no literacy [1-5]. CHWs can supplement the provision of contraceptive methods with counseling and referrals to clinic-based services [6]. This has been particularly true for women in underserved communities, whose ability to obtain contraceptive methods can be constrained by geographic and socioeconomic factors [6].

India has a long history of utilizing CHWs in rural family planning health care. The CHWs distribute non-clinical methods like condoms, oral contraceptive pills (OCPs), and emergency contraceptive pills (ECPs) as part of free-supply and social marketing schemes; however, distribution and availability of contraceptives has been hampered by challenges, resulting in restricted access to contraceptives., The Government of India (GOI) views poor commodity supply as a contributing factor to low use of spacing methods in India: $5 \%$ for condoms, $3 \%$ for OCPs, $2 \%$ for intrauterine devices (IUDs), and less than $1 \%$ for injectable contraceptives [10].

To improve access to contraceptives, the Ministry of Health and Family Welfare (MOHFW) decided to utilize the services of Accredited Social Health Activists (ASHAs). The ASHA cadre was introduced under the National Rural Health Mission in 2005 and there are approximately 830,000 ASHAs currently [11]. ASHAs are female volunteers drawn from the community who are responsible for a catchment population of
1000 and serve as the initial point of contact for all health-related issues at the community level. They provide safe motherhood initiatives, immunizations, deliveries, and referrals and escorts to health facilities. Studies have found ASHAs to be instrumental in increasing access to institutional deliveries and immunization [12]. While their service is voluntary, ASHAs can receive performance-based compensation for their work.

ASHAs offer community-level family planning services by providing condoms, OCPs, and ECPs; counseling eligible couples on contraceptive methods; helping women interested in OCPs be screened by health providers; and, referring women interested in IUDs to the nearest health facility. Each ASHA maintains a list of couples in her catchment area eligible for family planning.

\section{A new initiative}

To improve access to contraceptives, the MOHFW started a new initiative in 2011 for ASHAs to deliver male condoms, OCPs, and ECPs directly to households, and to receive small monetary payments for the methods sold. The new initiative, which was piloted in 233 districts in

Correspondence to: Sharmistha Basu, Ph.D, Programme Officer, Population Council, New Delhi, India, Tel: +91 9868492880; Email: basu_jnu@yahoo.com

Key words: community-based distribution, contraceptives, assessment, community health workers, scale-up

Received: October 14, 2017; Accepted: October 20, 2017; Published: October 30,2017 
17 states, also included a modified supply chain, changes in commodity packaging, communication strategies, standardized reporting forms, and guidelines for orienting ASHAs and other key implementers to the new initiative.

Traditionally, commodities from the national manufacturer were sent to state-level depots and then distributed down to district-level depots. Under the new initiative, the manufacturer shipped products directly to the district depots, which distributed commodities to block-level stores and health centers, where each ASHA obtained her supply of contraceptives (traveling up to 15 kilometers to do so). To track stocks at the ASHA-, block-, district-, and state-level, four new reporting formats were introduced.

In the pilot areas, the MOHFW discontinued the free supply of condoms, OCPs, and ECPs at the two lowest levels of health facilities, Sub-centers (SCs) and Primary Health Centers (PHCs), to encourage purchasing methods from the ASHAs. ASHAs began charging for methods-Indian rupee (Re.) 1 (US \$0.02) for a pack of three condoms, Re. 1 for a cycle of OCPs, and Re.2 (US \$0.04) for a pack of one ECP-and kept these payments to incentivize their efforts. The packaging was updated to display the new price; a unique stamp differentiated these products from the free supply which was available only at higher level facilities.

To inform communities about these changes and to renew their familiarity with ASHAs' distribution of contraceptives, communication campaigns designed materials for the pilot areas: leaflets and flipbooks for ASHAs; posters, wall paintings, and banners for community locations; and, posters and leaflets for health facilities. The initiative also received its own slogan, "ASHA se mango" or "Ask/demand from the ASHA."

In August 2011, the MOHFW distributed guidelines for implementing all elements of the initiative, including roles, responsibilities of key managers, and reporting formats. District-level officials oriented ASHAs, their managers, and health facility staff impacted by the changes in contraceptive provision.

The Family Planning Division of the MOHFW requested FHI 360 to undertake an operational assessment of the pilot in preparation for national scale-up. The assessment was designed to understand the acceptability of ASHAs selling contraceptives, and the experiences of ASHAs, their clients, and health providers and managers, with the new commodity charges, communication campaign, initiative orientation and reporting, and operation of the supply chain. The effectiveness and impact of the new initiative on overall contraceptive uptake in the pilot areas was beyond the scope of this assessment.

\section{Materials and methods}

The assessment was conducted in May 2012 in 6 of the 17 states (one district per state) where the initiative was being piloted: Assam (Jorhat), Bihar (Gaya), Madhya Pradesh (Mandla), Gujarat (Banaskantha), Odisha (Anugul), and Jammu and Kashmir (Udhampur). The MOHFW selected these districts to be geographically representative. In each district, PHCs operating the initiative for at least 3 months and with a minimum of 25 associated ASHAs were identified and one per district was selected. Fifteen ASHAs were systematically selected from each PHC for participation and completed semi-structured surveys focusing on the introduction and operation of the initiative, including barriers, facilitators, and recommendations for improvement.

For each ASHA interviewed, 5 women beneficiaries and 5 women non-beneficiaries were targeted for participation. Eligible women were married, 15-49 years of age, living with their spouse, and neither spouse was currently sterilized. Beneficiaries were women who had purchased condoms, OCPs, or ECPs from the ASHA at least once during the 3 months prior to interview. Non-beneficiaries were women who did not. Beneficiaries and non-beneficiaries were listed through a household enumeration exercise and then randomly selected for participation. All participants were surveyed about use of family planning, interactions with the ASHA, and knowledge, attitudes, and experiences with the initiative. Data from the beneficiaries are reported in this paper.

In-depth interviews were held with 38 managers and key implementers of the initiative at different administrative levels, including state, district, and block officials, medical officers at health facilities, and Auxiliary Nurse Midwives (ANMs), who managed the ASHAs under the initiative. These participants were selected purposively across the 6 states. They were interviewed about their knowledge of initiative, roles and responsibilities, supervision and management, stocks and procurement, challenges, and suggestions for improvement.

This assessment was reviewed and approved by the Protection of Human Subjects Committee of FHI 360 and by the institutional review board of the Centre for Media Studies in New Delhi. Oral informed consent was obtained from all participants.

\section{Results}

\section{Acceptability}

In total, 458 female beneficiaries participated in the survey and their characteristics are summarized in Table 1 . Women were on average 28 years old with a mean of 2 children: most were interested in avoiding or delaying pregnancy ( $61 \%$ and $33 \%$, respectively). Aside from family planning, beneficiaries also received other maternal and child health services from the ASHAs. In the 3 months prior to the survey, beneficiaries and their husbands primarily received OCPs and condoms from the ASHAs: only 5\% received ECPs. Couples had been using their ASHA-sourced method for a mean of 14.6 months, indicating that many began using their methods before the initiative started. About a quarter (22\%), however, had potentially initiated their method under the initiative (data not shown).

Overall, $75 \%$ of beneficiaries were "completely satisfied" with the initiative, and 20\% were "somewhat satisfied." Most beneficiaries reported the ASHA brought the method directly to their home. When the need for resupply arose, 53\% reported the ASHA remembered the resupply, and $43 \%$ said she or her husband contacted the ASHA to request additional supplies; only $6 \%$ of the beneficiaries had difficulty contacting the ASHA. Contraceptive provision was based on available methods, and that the study was not able to assess contraceptive preferences beyond evaluating what was requested and received.

Across the 6 study areas, 92 ASHAs completed the survey. These women were on average 34 years old and had been working as an ASHA for a mean of 4 years (Table 2). About half (52\%) of the ASHAs reported the initiative had increased their number of contraceptive acceptors, $20 \%$ thought it had decreased their numbers, and $26 \%$ felt there was no impact. The majority of ASHAs (86\%) believed the initiative would be successful over the long term because the methods cost less than those for sale in shops, and that the couples no longer had to travel to purchase their methods.

\section{New charges}

Although 50\% of the ASHAs reported a positive response from their communities when they started to charge for contraceptives, the 
Basu S (2017) An assessment of the government of India's initiative on contraceptives at the doorstep by Accredited Social Health Activists (ASHAs): Recommendations for national scale-up

Table 1. Beneficiary characteristics and experiences with the initiative

\begin{tabular}{|c|c|}
\hline & Beneficiaries \\
\hline & $n=458$ \\
\hline \multicolumn{2}{|l|}{ Beneficiary Characteristics } \\
\hline Age, mean (years) & 28.4 \\
\hline Number living children, mean & 2.0 \\
\hline \multicolumn{2}{|l|}{ Fertility desires (\%) } \\
\hline Would like no more children & 61 \\
\hline $\begin{array}{l}\text { Would like to delay pregnancy for } 2 \text { yrs } \\
\text { or more }\end{array}$ & 33 \\
\hline Would like another child within 2 years & 6 \\
\hline \multicolumn{2}{|l|}{$\begin{array}{l}\text { In past } 3 \text { months, received help from ASHA } \\
\text { for: }(\%)\end{array}$} \\
\hline Family planning & 100 \\
\hline Immunizations & 76 \\
\hline ORS & 47 \\
\hline Delivery assistance & 27 \\
\hline Nutrition & 21 \\
\hline Malaria & 18 \\
\hline Antenatal care & 17 \\
\hline \multicolumn{2}{|l|}{$\begin{array}{l}\text { In past } 3 \text { months, family planning methods } \\
\text { received from ASHA: (\%) }\end{array}$} \\
\hline Oral contraceptive pills & 59 \\
\hline Condoms & 54 \\
\hline Emergency contraceptive pills & 5 \\
\hline $\begin{array}{l}\text { Time using method received from ASHA, } \\
\text { mean (months) }\end{array}$ & 14.6 \\
\hline \multicolumn{2}{|l|}{ Acceptability } \\
\hline \multicolumn{2}{|l|}{ Overall satisfaction with initiative (\%) } \\
\hline Completely satisfied & 75 \\
\hline Somewhat satisfied & 20 \\
\hline Unsatisfied or Unsure & 5 \\
\hline \multicolumn{2}{|l|}{$\begin{array}{l}\text { Best way to describe how beneficiary gets } \\
\text { method from ASHA (\%) }\end{array}$} \\
\hline $\begin{array}{l}\text { ASHA brings method to the beneficiary's } \\
\text { home }\end{array}$ & 85 \\
\hline $\begin{array}{l}\text { Beneficiary meets the ASHA away from } \\
\text { the home }\end{array}$ & 10 \\
\hline \multicolumn{2}{|l|}{$\begin{array}{l}\text { Best way to describe how beneficiary } \\
\text { resupplies method with ASHA (\%) }\end{array}$} \\
\hline ASHA remembers it is time to resupply & 53 \\
\hline Beneficiary or husband contacts the ASHA & 43 \\
\hline Ever had problems locating the ASHA (\%) & 6 \\
\hline
\end{tabular}

responses varied greatly across the six study areas (Figure 1). ASHAs and their managers reported resistance to the new charges and that some clients refused to pay, making implementation of the initiative difficult. As a result, many ASHAs gave the initiative contraceptives for free, hoping to maintain their client base and then later phase in payments. Among beneficiaries, $50 \%$ of condom users, $25 \%$ of OCP users, and $52 \%$ of ECP users reported not paying the last time they obtained their method (data not shown).

To encourage uptake and resupply of commodities with the ASHAs, the free supply of contraceptives should have been discontinued; yet, $26 \%$ of ASHAs reported still having free-supply stocks, and $25 \%$ said free-supply methods were still being given at SC and PHC facilities in their areas. In the interviews, many managers expressed confusion and lack of guidance over how the existing free commodities should have been managed once low cost commodities were supplied.

\section{Communication and marketing}

ASHAs, managers, and beneficiaries reported that many of the initiative communication materials were not present in the 6 study
Table 2. ASHA characteristics and experiences with the initiative

\begin{tabular}{|c|c|}
\hline & ASHAs \\
\hline & $\mathrm{n}=92$ \\
\hline \multicolumn{2}{|l|}{ ASHA Characteristics } \\
\hline Age, mean (years) & 33.5 \\
\hline Time working as an ASHA, mean (years) & 4.3 \\
\hline \multicolumn{2}{|l|}{ Acceptability } \\
\hline \multicolumn{2}{|l|}{$\begin{array}{l}\text { Impact of initiative on FP client numbers } \\
(\%)\end{array}$} \\
\hline Acceptors increased & 52 \\
\hline Acceptors remained the same & 26 \\
\hline Acceptors decreased & 20 \\
\hline Don’t know & 2 \\
\hline $\begin{array}{l}\text { Believe initiative will be successful over } \\
\text { long term }(\%)\end{array}$ & 86 \\
\hline \multicolumn{2}{|l|}{ New Charges } \\
\hline \multicolumn{2}{|l|}{$\begin{array}{l}\text { Reaction from community when began } \\
\text { charging for methods }(\%)\end{array}$} \\
\hline Positive & 50 \\
\hline Neutral & 12 \\
\hline Negative & 32 \\
\hline No response & 6 \\
\hline ASHA still has free-supply stocks (\%) & 26 \\
\hline $\begin{array}{l}\text { ASHA reports free-supply at SC and PHC } \\
\text { facilities (\%) }\end{array}$ & 25 \\
\hline \multicolumn{2}{|l|}{ Communication and Marketing } \\
\hline $\begin{array}{l}\text { ASHA did not receive social marketing } \\
\text { materials }(\%)\end{array}$ & 62 \\
\hline $\begin{array}{l}\text { ASHA saw social marketing materials in } \\
\text { community }(\%)\end{array}$ & 58 \\
\hline \multicolumn{2}{|l|}{$\begin{array}{l}\text { Differences in packaging recalled by ASHA } \\
(\%)\end{array}$} \\
\hline Price marked on initiative packaging & 60 \\
\hline $\begin{array}{l}\text { Home-delivery-by-ASHA stamp on } \\
\text { initiative packaging }\end{array}$ & 23 \\
\hline ASHA reports no difference in packaging & 16 \\
\hline $\begin{array}{l}\text { ASHA reports incorrect differences or } \\
\text { "Don't Know" }\end{array}$ & 14 \\
\hline \multicolumn{2}{|l|}{ Orientation and Reporting } \\
\hline ASHA was oriented to initiative (\%) & 85 \\
\hline Among those oriented to initiative & $(n=78)$ \\
\hline \multicolumn{2}{|l|}{ Topics discussed during orientation (\%) } \\
\hline Counseling on condoms & 59 \\
\hline Counseling on OCPs & 58 \\
\hline Preparing eligible-couples register & 53 \\
\hline Maintaining eligible-couples register & 38 \\
\hline Counseling on ECPs & 31 \\
\hline Maintaining stocks of methods & 23 \\
\hline How to implement initiative & 22 \\
\hline Initiative payments & 21 \\
\hline ASHA maintaining register of sales (\%) & 64 \\
\hline $\begin{array}{l}\text { ASHA tracking stocks received and sold } \\
(\%)\end{array}$ & 82 \\
\hline $\begin{array}{l}\text { ASHA does not maintain any stock records } \\
(\%)\end{array}$ & 21 \\
\hline \multicolumn{2}{|l|}{ Supply Chain } \\
\hline \multicolumn{2}{|l|}{$\begin{array}{l}\text { ASHA did not have specific method on day } \\
\text { of survey }(\%)\end{array}$} \\
\hline No condoms & 29 \\
\hline No OCPs & 21 \\
\hline No ECs & 46 \\
\hline
\end{tabular}




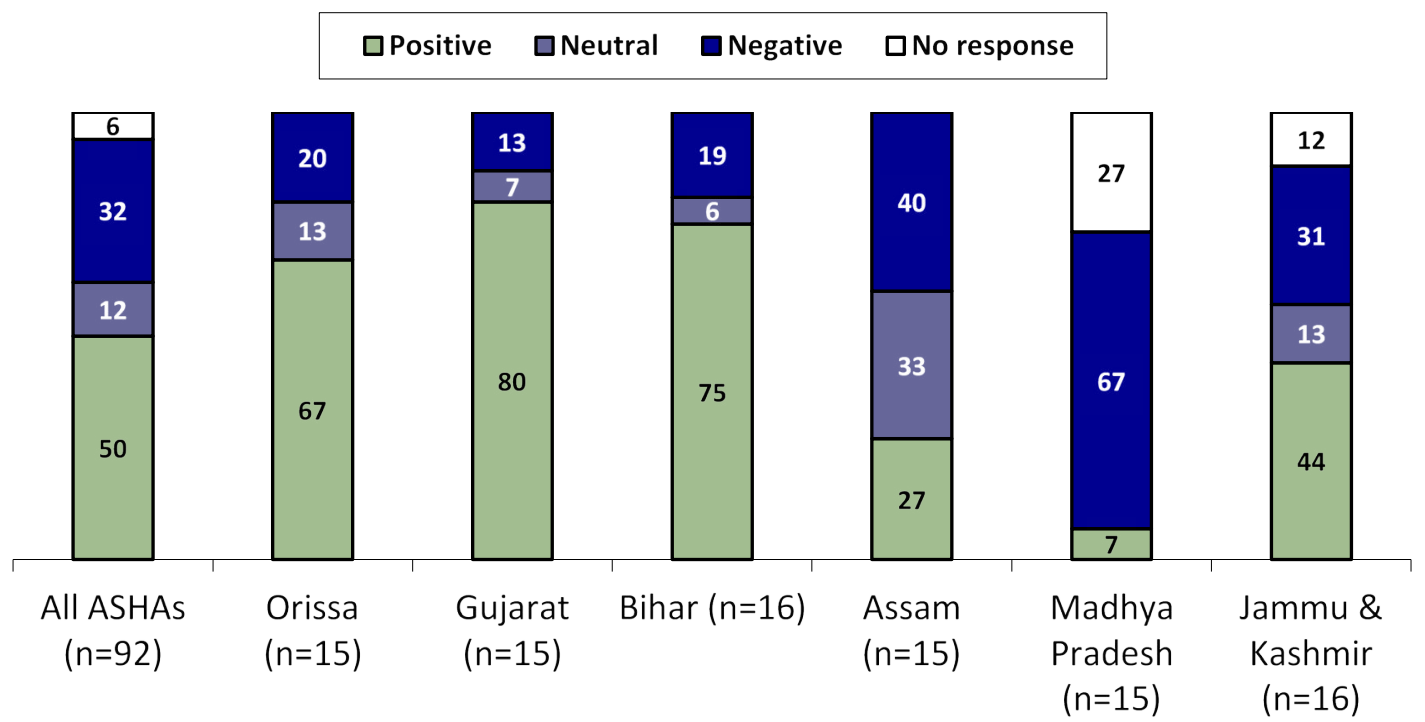

Figure 1. Community's Response to the Introduction of Charges for Methods, Percentage reported by ASHAs.

communities. Among the beneficiaries, $27 \%$ had seen wall writings, $20 \%$ had seen posters or banners, $5 \%$ had received leaflets or other printed materials, and only $8 \%$ were familiar with the tag line (data not shown). Among ASHAs, 62\% said they did not receive any materials to help them inform their communities and $58 \%$ did not see any advertising in their areas. Many ASHAs complained that the lack of marketing left couples uninformed on the initiative, resulting in community members questioning the legitimacy of the new charges.

Regarding the new packaging for commodities, $60 \%$ of ASHAs knew that the initiative supply had the price marked on the package, and $23 \%$ could describe the initiative's stamp on the package; yet, $16 \%$ said there was no difference between the initiative and free-supply packaging, and another $14 \%$ did not know the difference or reported incorrect changes. Several managers complained about the revised packaging. They felt the price was not distinctive enough and that the design and appearance of the initiative and free-supply packages were too similar, contributing to community confusion.

\section{Orientation and reporting}

Although most ASHAs reported being oriented to the initiative (85\%), many recalled the orientation focusing more on contraceptive counseling than on the initiative components. Fewer than $25 \%$ of ASHAs who participated in an orientation reported receiving training on essential elements such as stock maintenance and how to implement the initiative and payments. Managers reported that their orientation was primarily through reading and discussing the MOHFW's guidelines during routine management meetings, while ANMs were excluded from orientation activities.

Problems were seen with the new reporting formats introduced for tracking stock received and minimizing stock-outs. Among the ASHAs, $64 \%$ said they maintained a register of sales and $82 \%$ said they were tracking stocks received and sold; however, it was unclear whether the ASHAs were using the initiative's forms for this. Nearly a quarter of the ASHAs were not maintaining stock records. Managers attributed this problem to low levels of literacy among ASHAs and an overall lack of understanding on how to complete the forms. When ASHAs did not track sales correctly, errors compounded as data were reported upward to district-and state level. These may have contributed to stockouts and delayed resupply.

\section{Supply chain}

The manager interviews revealed confusion on supply management at all levels of the supply chain. Many state-level officials were unclear about the flow of commodities in the chain and where the supply originated. District-level managers reported that only one shipment of commodities had been received from the manufacturer, and most noted no guidance on how to procure additional shipments. Some areas began the initiative without any commodities. Moreover, a second, parallel supply chain was operating for the free-supply commodities still being provided at the upper-level facilities, complicating efforts to effectively manage either chain.

At the community level, many ASHAs were unsure how many condoms, OCPs, and ECPs they should stock. On the day of the survey, $20 \%$ or more of ASHAs did not have specific methods with them: nearly half (46\%) did not have ECPs. Some ASHAs (36\%) complained about not being supplied on time with methods, and their managers echoed this complaint. Similarly, $16 \%$ of beneficiaries reported that in the past 3 months their ASHA did not have the method they wanted (data not shown). However, the interviews were not able to obtain information on why stockouts and delayed supplies were occurring.

Clearly the new supply chain has more problems than even before. A steady supply may be critical to couples' interest in using methods and ASHAs enthusiasm about selling them, but will be addressed in a separate analysis.

\section{Discussion}

Nearly $90 \%$ of ASHAs thought that the initiative would be successful in the long term, and more than $70 \%$ of female beneficiaries were completely satisfied with the initiative. While these findings indicate that incentivizing community-based distribution of contraceptives by ASHAs is acceptable to communities and ASHAs, this assessment identified multiple operational challenges for the MOHFW and other settings considering similar programs.

The supply chain was revised to streamline distribution and avoid delays; however, it was unclear if this truly improved the supply chain. confusion appeared at the state-, district-, and block-levels, leaving areas with inconsistent supplies of initiative contraceptives. Similar to 
findings in other studies, once the commodities reached the ASHAs, distribution was generally reliable and few couples complained about the availability of their methods [4,13]. Clearer guidance on stock handling could alleviate confusion on procurement and managing the free-supply stocks. The existence of the free-supply stocks hampered efforts to transition communities to a system of payment for condoms, OCPs, and ECPs, and in some areas generated animosity and distrust towards the ASHAs. These feelings could negatively impact other services offered by the ASHAs.

The assessment found weak implementation of the communication strategy. Little can be concluded about the effectiveness of the communication campaign and its materials, as there was so little evidence of the campaign in the communities assessed.

Many ASHAs had difficulty with new reporting requirements. ASHAs, who on the whole have low levels of literacy, found the multiple new formats and registers burdensome. For their other responsibilities, ASHAs frequently seek the support from ANMs: a 2009 five-state evaluation noted that over three quarters of ASHAs expressed a need for support from ANMs [14]. Under this initiative, however, the ANMs were omitted from the guidelines and orientation requirements, leaving them poorly equipped to support the ASHAs.

Strengths of this evaluation were that it provided a detailed assessment of a novel program in a high-need area, and that results could be transformed into practical policy recommendations.

A limitation is that sample size calculations were not generated for this assessment. State wise analysis was thus not possible. Sampling was limited by cost and time and findings are not generalizable beyond the surveyed areas. Another limitation was given the limited time the new initiative was on the field for pilot, we could only undertake an operational assessment. Thus, this was not a formal evaluation to understand what difference the ASHAs made to contraceptive uptake in rural India, which was beyond the scope of this study. We have explored only branding and packaging as part of marketing, which limited ability to draw conclusions about a larger social marketing strategy. However, results provide insight into the initiative's implementation in similar settings and may inform recommendations for strengthening the initiative and informing national scale-up. To our knowledge there are no other similar studies.

Operational challenges can be addressed with strengthened guidelines and an improved orientation process. To facilitate these improvements and the national roll-out of the initiative, the following recommendations were shared with the MOHFW:

Involve the state government in the supply chain. Bypassing the state level led to confusion at the district level on whom to contact when supplies were depleted. Involving the state government in disbursing and maintaining stock records will be essential for increasing ownership and accountability.

Use a single supply chain for the free- and initiative-supplies. The same supply chain and reporting mechanism should be used for both types of commodities.

Clearly differentiate the packaging of initiative commodities. An image of a 1-Rupee coin could be placed on the front of initiative methods to help distinguish between free- and initiative-supplies.

Develop guidelines for withdrawing the free-supply commodities. Updated initiative guidelines should include directions on withdrawing the free-supply commodities.
Strengthen the communication campaign and social marketing. Improving communication can increase community awareness and acceptance of the new charges. ANMs, health providers, and other officials could visit areas of high resistance to endorse the initiative.

Simplify and streamline the reporting. Modified forms should include both initiative- and free-supply commodities and should be incorporated into the health management information system. Mobile technology could be adopted for reporting by ASHAs.

Involve ANMs in the initiative. ANMs should have a well-defined role to orient the ASHAs, and to provide oversight and supportive supervision. ASHAs' reporting burden could also be shifted to ANMs, who have higher levels of literacy.

Strengthen the orientation for all implementers. An improved orientation on the initiative guidelines provides opportunities for state-, district-, block-, and community-level implementers to fully understand their roles and responsibilities.

Caution should be used in interpreting results of this operational assessment, since it is not possible to say whether the program has increased contraceptive uptake or solved other pre-existing problems not directly linked to the ASHA program. The above recommendations may increase the efficiency and effectiveness of the initiative, though this should be demonstrated through well-planned monitoring and evaluation. Results of implementation may be relevant to community-based family planning programs in other settings who want to strengthen their commodity supply chain, improve program management and reporting, and encourage CHWs to successfully improve family planning provision.

\section{Acknowledgement}

Funding for this assessment was provided by the United States Agency for International Development (USAID) under the Program Research for Strengthening Services (PROGRESS) Project (GPO-A-00-08-00001-00). The views expressed in this publication do not necessarily reflect those of FHI 360 or USAID.

\section{Conflict of interest}

The authors have no conflict of interest to disclose.

\section{References}

1. Johri L, Panwar DS, Lundgren R. Introduction of the Standard Day Method in CARE-India's Community-Based Reproductive Health Programs. Washington, DC: Georgetown University, Institute for Reproductive Health.

2. Georgetown University, Institute for Reproductive Health (IRH). Lactational Amenorrhea Method (LAM) Projects in India. Washington, DC: IRH.

3. Khan ME, Hossain SM, Rahman M. Introduction of Emergency Contraception in Bangladesh: Using Operations Research for Policy Decisions. New York: Population Council.

4. Hoke TH, Wheeler SB, Lynd K, Green MS, Razafindravony BH, et al. (2012) Community-based provision of injectable contraceptives in Madagascar: task shifting to expand access to injectable contraceptives. Health Policy Plan 27: 52-59. [Crossref]

5. Prata N, Gessessew A, Cartwright A, Fraser A (2011) Provision of injectable contraceptives in Ethiopia through community-based reproductive health agents. Bull World Health Organ 89: 556-564. [Crossref]

6. U.S. Agency for International Development (USAID). Family Planning High Impact Practices: Community Health Workers. Washington, DC: USAID.

7. Philips JF, Greene WI, Jackson EF. Lessons from Community-Based Distribution of Family Planning in Africa. Working Paper No. 121. New York: Population Council.

8. Huber D, Saeedi N, Samadi AK (2010) Achieving success with family planning in rural Afghanistan. Bull World Health Organ 88: 227-231. [Crossref] 
Basu S (2017) An assessment of the government of India's initiative on contraceptives at the doorstep by Accredited Social Health Activists (ASHAs): Recommendations for national scale-up

9. Bhatia Kavita (2014) Performance-Based Incentives of the ASHA scheme: Stakeholders Perspectives. Economic and Political Weekly.49(22): 145-151.

10. International Institute for Population Sciences (IIPS), Macro International. National Family Health Survey (NFHS-3), 2005-06: India. Mumbai, India: IIPS.

11. Ministry of Health and Family Welfare (MOHFW). Update on the ASHA programme, New Delhi: MOHFW, Government of India. 2011.
12. International Institute for Population Sciences (IIPS). Concurrent Assessment of National Rural Health Mission (NRHM) 2009: Mumbai, India IIPS; 2011.

13. Hasselberg, Erin, and Julia Byington. 2010. Supply Chain Models and Consideration for Community-Based Distribution Programs: A Program Manager's Guide. Arlington, Va: John Snow, Inc.

14. United Nations Population Fund. 2009. Concurrent Assessment of Janani Suraksha Yojna (JSY) scheme in selected States of India, 2008.

Copyright: (2017 Basu S. This is an open-access article distributed under the terms of the Creative Commons Attribution License, which permits unrestricted use, distribution, and reproduction in any medium, provided the original author and source are credited. 